\title{
Memorial da América Latina
}

Fernando Leça

Diretor presidente da Fundação Memorial da América Latina.

Foi membro do Conselho Superior da Fapesp e do Conselho Deliberativo do IEA - Instituto de Estudos Avançados da USP.

E-mail: fleca@sp.gov.br

Plantado em 84.480 m²$^{2}$, no bairro da Barra Funda, o Memorial da América Latina é um convite permanente às manifestações artísticas e científicas latino-americanas; um apelo para que elas façam do conjunto arquitetônico projetado por Oscar Niemeyer a sua casa em São Paulo.

A idéia generosa de solidariedade e união latino-americana é tão antiga quanto as lutas no século XIX de Simón Bolívar, José Marti e San Martin por um continente livre e fraterno. A "Pátria Grande" vislumbrada por eles, porém, ficou esquecida no passado. Nos anos 1980, especialmente os brasileiros precisavam redescobrir a América. Os hispano-americanos também pareciam desconhecer a proximidade histórica, lingüística e cultural de seus vizinhos de língua portuguesa.

Era preciso lembrar quem somos a nós mesmos. Para isso foi inaugurado em 18 de março de 1989 o Memorial da América Latina, com o conceito e o projeto cultural

A escultura A Grande Mão, de Oscar Niemeyer, tornou-se o símbolo por excelência do Memorial e um marco urbano. Ela está pintada em muros e túneis da cidade, ao lado de reproduções dos principais pontos turísticos de São Paulo. Localizada na Praça Cívica, foi erguida em concreto aparente de 7 metros de altura. Na sua palma, há o mapa do subcontinente americano em baixo-relevo, pintado em esmalte sintético vermelho, lembrando sangue a escorrer.

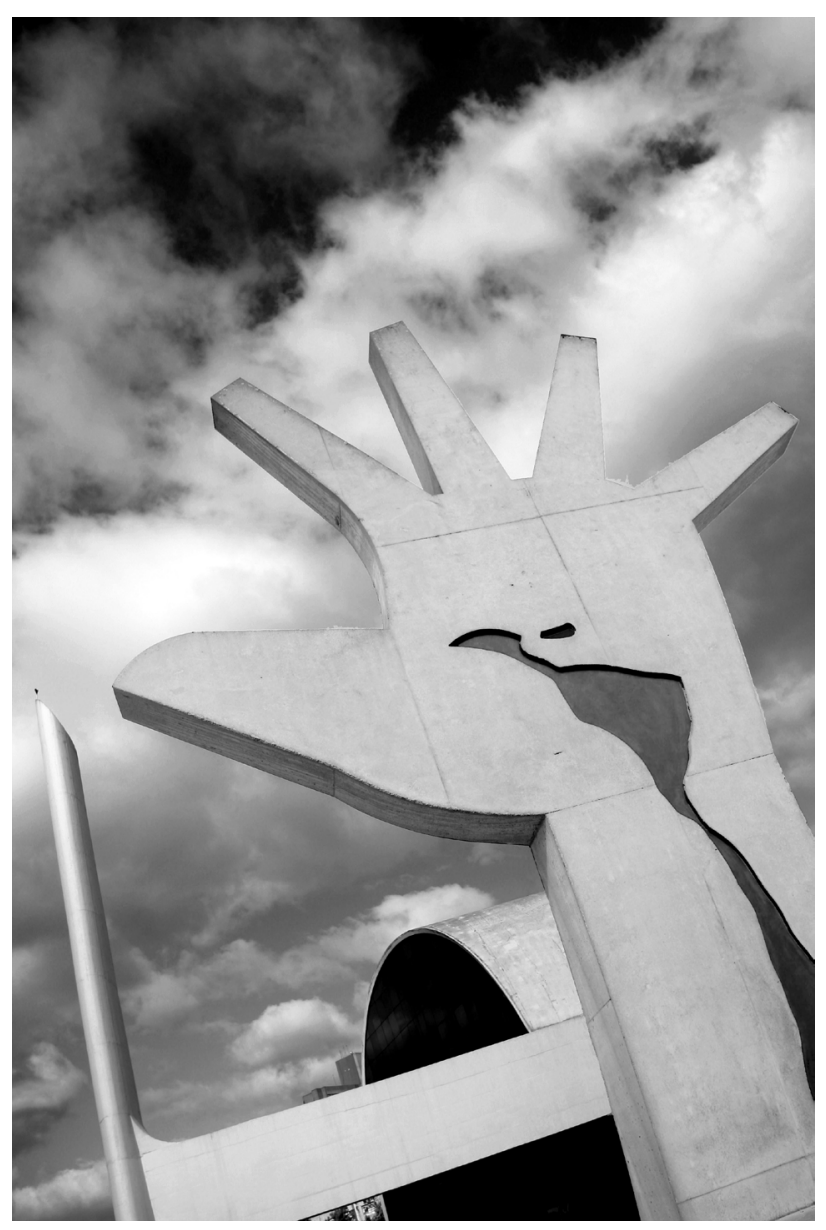


comunicação \& educação • Ano XIII • Número 1 • jan/abr 2008

desenvolvidos pelo antropólogo Darcy Ribeiro. Assim, o Memorial nasceu com a missão de estreitar as relações culturais, políticas, econômicas e sociais do Brasil com os demais países da América Latina.

Desde então vem cumprindo seu papel: fomenta a pesquisa e divulga seus resultados; apóia a expressão da identidade latino-americana e incentiva seu desenvolvimento criativo; coordena iniciativas de instituições científicas, artísticas e educacionais do Brasil e de outros países ibero-americanos; e difunde a história dos povos latino-americanos às novas gerações de estudantes.

O Memorial da América Latina é uma fundação de direito público, sem fins lucrativos, instalado perto do centro de São Paulo, no bairro da Barra Funda. Fica ao lado do terminal da Barra Funda, que reúne estação de metrô, trem e ônibus municipais e intermunicipais.

Foi estruturado com órgãos e serviços para cumprir a missão de integrar os países da América Latina e vem cumprindo seu papel, fomentando todas as formas de expressão da identidade latino-americana e de incentivo à criatividade cultural; coordenando iniciativas internacionais de interesse dos povos latino-americanos; mantendo um centro de informações básicas da realidade latino-americana através de uma biblioteca especializada; difundindo o conhecimento da história dos povos latino-americanos nos projetos de visitação escolar; incentivando a cooperação entre as instituições científicas, artísticas e educacionais do Brasil e de outros países ibero-americanos.

Estes órgãos envolvem os seguintes espaços, que trabalham de forma interdisciplinar.

\section{AUDITÓRIO SIMÓN BOLÍVAR}

Com capacidade para 1.609 pessoas, o Auditório é formado por duas platéias separadas pelo palco, onde são apresentados espetáculos artísticos. Para funcionar como centro de convenções, na realização de congressos e seminários, há a opção para utilização de uma só platéia, com 876 lugares. O espaço já foi utilizado diversas vezes para recepcionar chefes de Estado, como o norte-americano Bill Clinton, o cubano Fidel Castro, o venezuelano Hugo Chávez, entre outros.

Investindo na formação de público para a música erudita, o Memorial apresenta duas vezes por mês concertos da Orquestra Jazz Sinfônica (no estilo das big bands, a Jazz traz sempre um convidado especial para acompanhá-la), a Banda Sinfônica do Estado de São Paulo, além de outros corpos musicais ligados ao Centro Musical Tom Jobim.

Com a Jazz Sinfônica, já se apresentaram músicos como Tom Jobim, John Pizzarelli, Jane Monheit, Edu Lobo, Zizi Possi, João Bosco, Francis Hime, Eugênia Melo e Castro, Paulinho da Viola, Caetano Veloso, entre muitos outros. $\mathrm{Na}$ área internacional, estiveram no Auditório do Memorial o grupo cubano Irakêre, Paquito D'Rivera, Gonzalo Rubalcaba, Maria Rivas, Wilfrido Vargas, Mercedes Sosa, Armando Manzanero, Paco de Lucia, entre outros. 
Durante alguns dias do ano, o Auditório, que é formado por duas platéias, se transforma em duas salas de cinema e são exibidos os filmes que compõem o Festival de Cinema Latino-americano de São Paulo, evento que se realiza no mês de julho e que já teve duas edições.

Em outubro e novembro, é a vez de o Memorial participar da Mostra Internacional de Cinema de São Paulo, exibindo filmes durante todo o dia e abrigando o Festival da Juventude. E o Anima Mundi, festival de cinema de animação, com as mais variadas técnicas, também acontece aqui há três anos. Oficinas com técnicas de animação são oferecidas gratuitamente ao público, que lota o foyer do Auditório. O espaço abriga as seguintes obras de arte: Agora, painel em óleo sobre tela, de Vítor Arruda; Pomba, escultura em bronze, de Alfredo Ceschiatti; Sem Titulo, tapeçaria, de Tomie Ohtake; Homenagem ao teatro, painel em óleo sobre tela, de Carlos Scliar.

\section{BIBLIOTECA LATINO-AMERICANA VICTOR CIVITA}

A Biblioteca tem por objetivo reunir a expressão cultural relevante de cada um dos países da América Latina, contribuindo de forma eficaz para o intercâmbio de informações entre pesquisadores.

O acervo de livros é especializado em cultura latino-americana e conta atualmente com 30 mil volumes. Oferece serviços como levantamentos bibliográficos, tanto no acervo local como em CD-ROM e na internet.

A videoteca tem um acervo com 2 mil fitas de vídeo e DVDs, entre documentários, comédias e dramas importantes da cinematografia internacional e, principalmente, da latino-americana.

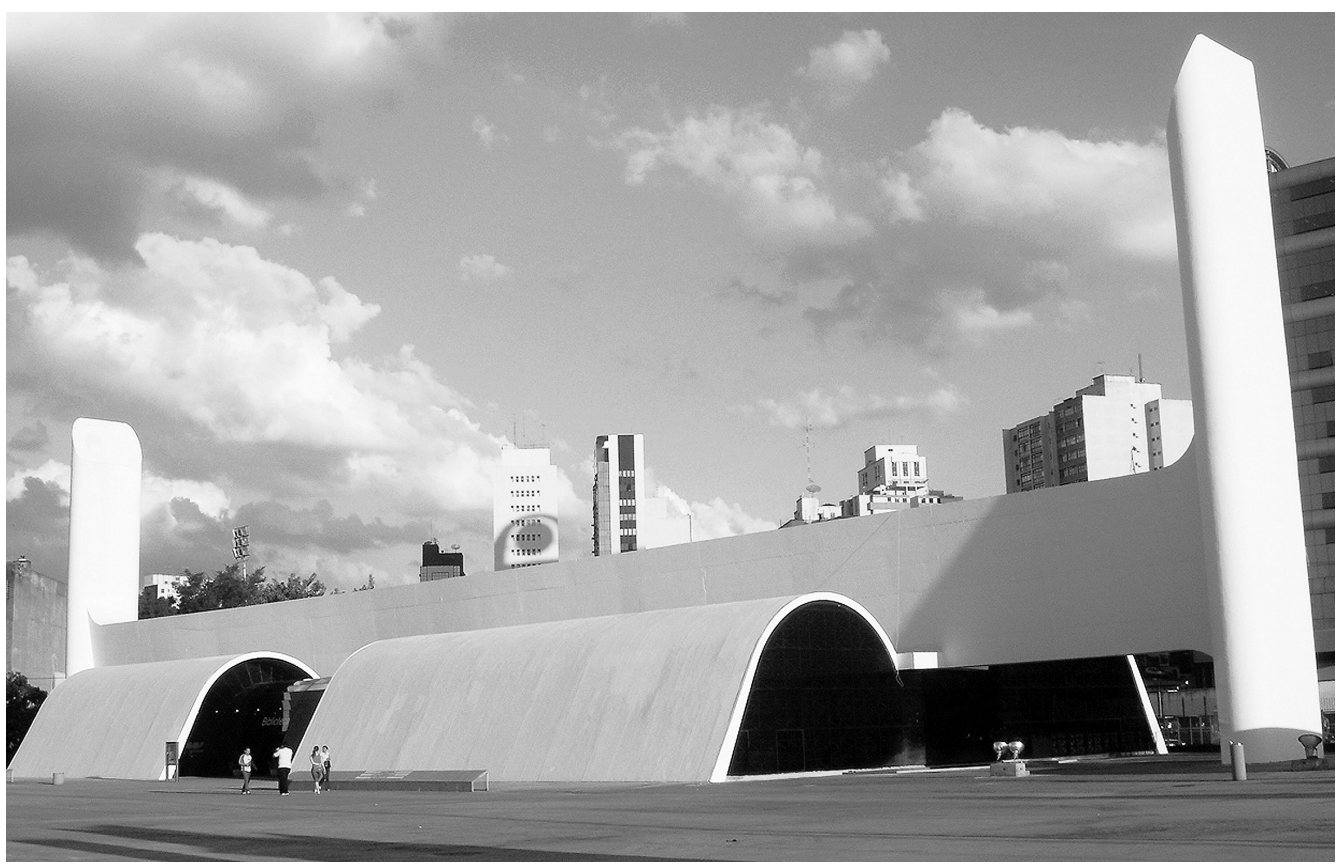

Biblioteca. 
A fonoteca possui 1.600 fitas cassetes e 400 discos de música latino-americana, que podem ser consultados para pesquisas. Atualmente, está em andamento a criação Núcleo de Pesquisa e Documentação Latino-Americana, que tem como finalidade a preservação da memória musical dos países da América Latina, através de pesquisa, documentação, divulgação e estudo de suas diversas manifestações, sejam folclóricas, populares, sejam eruditas. O espaço abriga as seguintes obras de arte: Homenagem a Clay Gama de Carvalho, painel em cerâmica, de Mário Gruber; América Latina, painel em vidro, de Marianne Peretti.

\section{SALÃO DE ATOS}

O Salão de Atos é destinado, em dias especiais, a solenidades e recepções oficiais do governo do Estado de São Paulo, especialmente aquelas ligadas às questões do continente. Nos dias comuns, está aberto ao público, que ali aprecia o Painel Tiradentes, de Cândido Portinari, além dos seis painéis heráldicos, em baixo-relevo, criados por Poty e Carybé. Os painéis heráldicos são assim descritos:

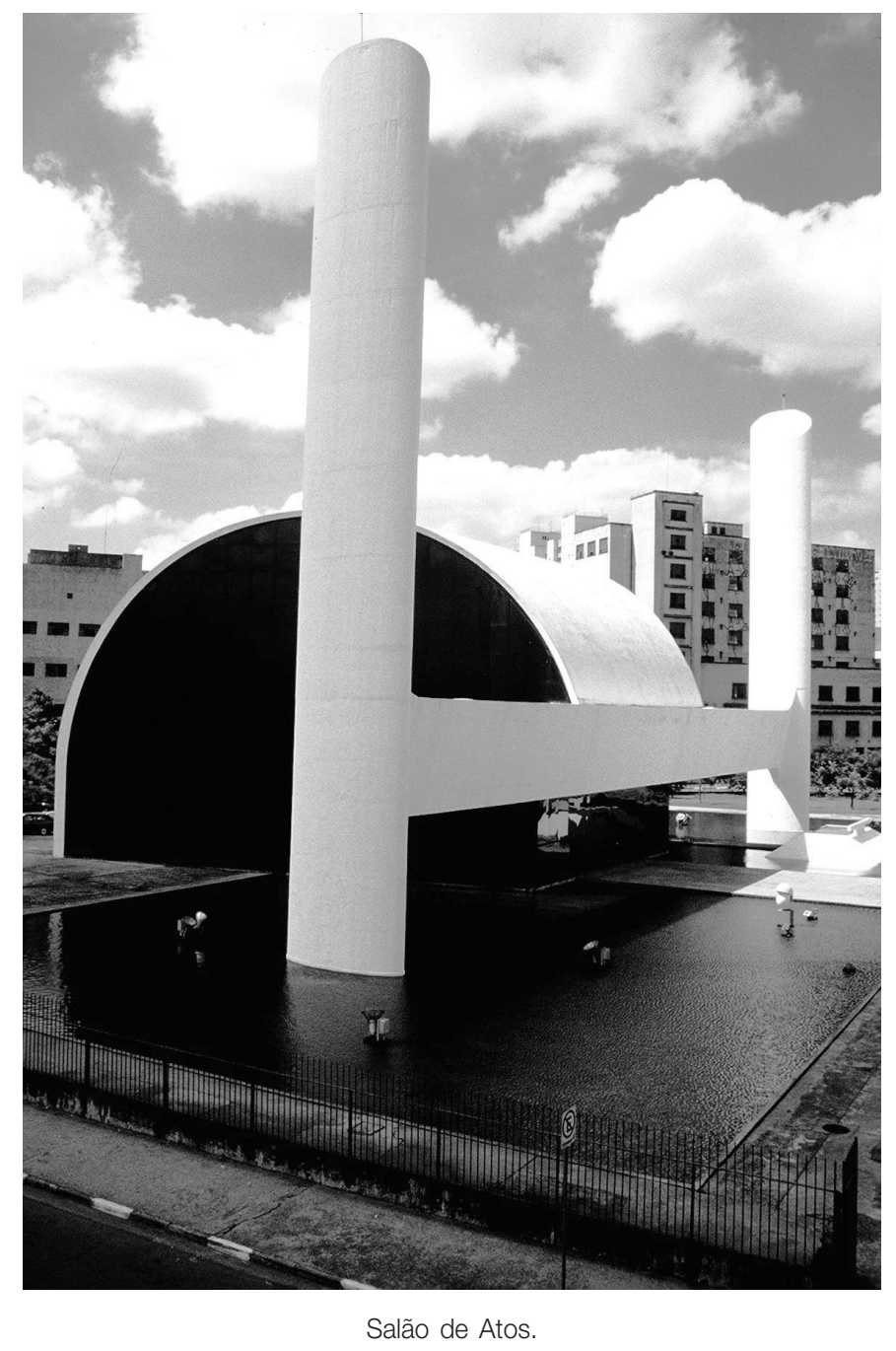


- Painel dos Povos Pré-colombianos: homenageia os povos que habitavam o continente antes da chegada do europeu, dando ênfase aos Astecas, Maias e Incas.

- Painel dos Povos Afros: revela não só os aspectos da escravidão, mas também a rica contribuição cultural trazida por esses povos.

- Painel dos Conquistadores: retrata a chegada do europeu à América, mostrando o choque e os conflitos gerados, além da temática da miscigenação.

- Painel dos Imigrantes: mostra o papel dos imigrantes na trajetória histórica da América Latina, não só devido à bagagem cultural e mestiçagem, mas pela riquíssima contribuição do seu trabalho.

- Painel dos Libertadores: apresenta o momento em que os latino-americanos, conscientes da dominação européia, lutam em busca de liberdade, formando os diversos Estados independentes.

- Painel dos Edificadores: demonstra o desenvolvimento tecnológico e a contribuição do trabalho de todos os povos citados, destacando o homem comum: o trabalhador braçal.

\section{PAVILHÃO DA CRIATIVIDADE DARCY RIBEIRO}

Ligado à Diretoria de Atividades Culturais, o Pavilhão da Criatividade possui uma exposição permanente de arte popular latino-americana que reúne, em especial, trabalhos dos países com forte influência das civilizações pré-colombianas: Bolívia, México, Guatemala, Peru e Equador. Chile, Uruguai, Paraguai também estão representados. São cerca de 4 mil obras.

O Pavilhão abriga, também, uma exposição de arte popular brasileira, uma ala para exposições temporárias e um espaço para exibição de filmes. Em um pedaço do solo do Pavilhão, coberto por um vidro transparente, o público pode conhecer um pouco do folclore latino-americano. A dupla de artistas Gepp e Maia criou uma maquete da América Latina, utilizando material diverso em quase mil pequenas peças.

\section{PRAÇA CÍVICA}

É um amplo espaço aberto, destinado ao encontro de multidão e manifestações culturais, onde se encontra também um dos símbolos do Memorial: a escultura A Grande Mão, feita pelo arquiteto Oscar Niemeyer. A Praça é dividida em duas partes por uma avenida e unida por uma enorme passarela. O espaço abriga as seguintes obras de arte: Flor Tropical, escultura em aço pintado, de Franz Weissmann; A Grande Mão, escultura em concreto, de Oscar Niemeyer; Torso Negro, escultura, de Vera Torres; Ventana Negra, escultura, de Sebastián; busto de Simón Bolívar, escultura, de Vitorio Camacho; Integração, escultura em mármore, de Bruno Giorgi; Etnias: Do Primeiro 
e Sempre Brasil, painel em cerâmica, bronze e alumínio, de Maria Bonomi (localizado no Portão 1).

\section{ANEXO DOS CONGRESSISTAS}

Espaço reservado a atividades acadêmicas, diplomáticas, encontros intelectuais, pequenas exposições e comemorações de datas nacionais. Abriga a obra de arte Futura Memória, painel em concreto e terracota, de Maria Bonomi.

\section{EDIFÍCIO DA ADMINISTRAÇÃO}

Sede administrativa do Memorial, que envolve a presidência e as diretorias Administrativa/Financeira e de Atividades Culturais, além do CBEAL - Centro Brasileiro de Estudos da América Latina.

A diretoria de Atividades Culturais coordena eventos artísticos, com destaque para aqueles que expressam a identidade latino-americana. Estão sob sua responsabilidade o Pavilhão da Criatividade e o Auditório Simón Bolívar.

O CBEAL foi criado para desenvolver estudos relativos a temas latino-americanos sob uma perspectiva interdisciplinar. Dentre os objetivos do CBEAL, destacam-se a pesquisa, a disseminação e a documentação das mais importantes manifestações culturais e intelectuais produzidas no continente. Para isso, coordena as atividades da Biblioteca Latino-Americana e do Departamento de Publicações do Memorial.

O Centro também atua como núcleo de discussão sobre os múltiplos e complexos aspectos da identidade latino-americana, acolhendo e divulgando o pensamento crítico de especialistas brasileiros e internacionais, através da realização de seminários, encontros, debates e colóquios. O espaço abriga a obra de arte Sem Título, painel em óleo sobre tela, de Vallandro Keating.

\section{GALERIA MARTA TRABA DE ARTE LATINO-AMERICANA}

A Fundação Memorial da América Latina inaugurou no dia 26 de março de 1998 uma galeria de arte projetada por Oscar Niemeyer, com duas salas equipadas dentro dos padrões museológicos. O espaço prioriza a arte latino-americana.

\section{VISITAS MONITORADAS}

Grupos de turistas ou escolares podem agendar visitas guiadas, com antecedência. No passeio, os visitantes percorrem todos os espaços, acompanhados por monitores especializados, que enfocam os aspectos historiográficos, artísticos e culturais da América Latina. 
O Memorial tem uma série de projetos que acontecem todos os dias do ano. Na área acadêmica, um dos que mais vêm se destacando é a Cátedra Memorial da América Latina.

\section{O que é a Cátedra}

A Cátedra Memorial da América Latina é um projeto acadêmico que une a Fundação Memorial, por meio do seu Centro Brasileiro de Estudos da América Latina (CBEAL) e as três universidades públicas paulistas - USP, Unicamp e Unesp. Trata-se de programa de pesquisa e docência, desenvolvido semestralmente por pesquisadores, brasileiros e estrangeiros, de comprovada competência em suas áreas.

O programa objetiva promover o desenvolvimento de temas relevantes, mediante estudo sistemático das realidades culturais, históricas e políticas dos países latino-americanos. Com caráter multidisciplinar, a Cátedra une a excelência das três universidades à experiência de empresas que atuam na região, co-partícipes do programa de formação e aperfeiçoamento de pesquisadores.

Conta também com uma Comissão de Orientação, composta de representantes do Memorial, das três universidades citadas, da Fapesp e das secretarias estaduais de Cultura e de Ciência e Tecnologia. Os recursos do programa advêm do Fundo Cátedra Memorial da América Latina, resultante de cotizações anuais de empresas mantenedoras, assim como das entidades instituidoras.

As atividades da Cátedra têm lugar nas universidades, no Memorial da América Latina e em empresas, comportando cursos de curta duração, seminários, orientação de pesquisa e conferências, cujos resultados são publicados sob a responsabilidade do Memorial da América Latina.

Os pesquisadores selecionados pela Comissão recebem uma bolsa de estudos e ficam um semestre no Memorial e nos campi das três universidades, onde assistem a aulas, participam de simpósios, conferências e de outras atividades curriculares, para, ao final, redigirem um ensaio.

A viabilidade da integração econômica dos países amazônicos, a questão ambiental ou a interdependência energética no continente são exemplos de temas que podem desdobrar-se em diferentes pesquisas e dissertações. Os temas abordados estão relacionados aos processos de inovação tecnológica e integração latino-americana no mundo globalizado, educação e cultura, processos de internacionalização das universidades, desenvolvimento sustentável, energia, comunicações, mercado e processos de trabalho, sistemas previdenciários, proteção social e pobreza, entre outros.

Esses e outros projetos fazem do Memorial uma instituição sem precedentes no nosso continente, que recebe quase um milhão de visitantes ao ano. $\mathrm{E}$ a meta é ultrapassar esta marca em 2007. 


\section{Serviço}

\section{Memorial da América Latina}

Av. Auro Soares de Moura Andrade, 664, Barra Funda (ao lado do metrô). Funcionamento: de terça-feira a domingo, das 9 às 18 horas (com exceção da Biblioteca Latino-Americana Victor Civita, que funciona de segunda a sextafeira, das 9 às 18 horas, e aos sábados, das 9 às 15 horas).

Entrada franca.

Telefone: (11) 3823-4600. Serviço de monitoria pode ser agendado pelos telefones (11) 3823-4655 e 3823-4667, ou pelo e-mail: monitoria@memorial.sp.gov.br.

Resumo: Plantado em $84.480 \mathrm{~m}^{2}$, no bairro da Barra Funda, o Memorial da América Latina é um convite permanente às manifestações artísticas e científicas latino-americanas; um apelo para que elas façam do conjunto arquitetônico projetado por Oscar Niemeyer a sua casa em São Paulo. Para cumprir sua missão de integrar os países latino-americanos, o Memorial conta com espaços privilegiados como o Auditório Simón Bolívar, o Pavilhão da Criatividade Darcy Ribeiro, a Galeria Marta Traba, a Biblioteca Latino-Americana Victor Civita e o Salão de Atos.

Palavras-chave: Memorial da América Latina, cultura, arte, América Latina, educação.
Abstract: The Memorial da América Latina (Memorial of Latin America) is a $84,480 \mathrm{~m}^{2}$ architectonical complex created by Oscar Niemeyer and located in the Barra Funda neighborhood. Its mission is to integrate the Latin-American countries. To accomplish this mission, the Memorial permanently invites Latin-American artists and cientists to join and adopt it as it were their own homes in São Paulo. The Memorial counts on noteworthy buildings like the Simón Bolívar Auditorium, the Darcy Ribeiro Creativity Pavillion, the Marta Traba Gallery, the Victor Civita Latin-American Library and the Acts Room.

Keywords: Memorial of Latin America, culture, art, Latin America, education. 